\title{
Two Microcatheter Technique for Embolization of Arteriovenous Fistula with Liquid Embolic Agent
}

\author{
Lin-Bo Zhao, MD', ', Jae Ho Shim, MD', Dong-geun Lee, MD', Dae Chul Suh, MD'
}

Problem with embolization of arteriovenous fistula (AVF) with liquid embolic agent is its over-penetration into the veins or regurgitation to the proximal feeder without reaching the shunt point. We present a technique that controls the flow of AVF during embolization. Two microcatheter technique consists of positioning one microcatheter close to the AVF for embolization, and with another microcatheter at the proximal feeding artery to control the AVF flow by coiling. Selective angiograms obtained using a distally positioned microcatheter before and after coiling, were compared how much stagnant effect was achieved. Using two microcatheter technique, AVF occlusion was achieved with good penetration of glue to the venous side of the AVF. Its advantage is the ability to push glue into the shunt without causing over-penetration of glue or its reflux along the feeder. Two microcatheter technique was safe and effective in glue embolization of AVF and also expected to be applied with other liquid embolic agent like Onyx.

Key Words : Embolization, Therapeutic/methods; Catheters; Arteriovenous fistula

The efficacy of transarterial embolization of arteriovenous fistula (AVF) using liquid embolic agent can be maximized when the embolic material penetrates the AVF shunt into the adjacent draining vein. A major problem of embolization is how to precisely deliver the embolic material to the sites of the AVF. When selective

\footnotetext{
1Department of Radiology and Research Institute of Radiology, University of Ulsan, College of Medicine, Asan Medical Center, Seoul, Korea; 'Department of Radiology, First Affiliated Hospital of Nanjing Medical University, Nanjing, China

Received January 13, 2014; accepted

after revision February 12, 2014.

Correspondence to: Dae Chul Suh, M.D., Ph.D, Department of Radiology, Asan Medical Center, University of Ulsan, College of Medicine, 86 Asanbyeongwon-gil, Songpa-gu, Seoul 138-736, Korea.

Tel. 82.2.3010.4366 Fax. 82.2.476.0090

E-mail: dcsuh@amc.seoul.kr

This is an Open Access article distributed under the terms of the Creative Commons Attribution Non-Commercial License (http://creativecommons.org/licenses/by-nc/3.0) which permits unrestricted non-commercial use, distribution, and reproduction in any medium, provided the original work is properly cited.
}

positioning of the microcatheter into the AVF shunt is difficult, embolization can result in proximal feeder occlusion without reaching the shunt. When the shunt flow is too rapid to be safely occluded, embolic material can be over-penetrated into the vein, thus resulting in serious disturbance of venous drainage [1-3].

Flow control has been achieved by rapid injection of high concentration glue, by induction of stagnant flow with temporary balloon occlusion of the feeder or by using transvenous approach $[4,5]$. But sometimes, selective catheterization of the microcatheter close to the AVF site is difficult to achieve in an AVF with a relatively small and tortuous feeding artery [6]. By using the so-called wedged-catheter position, lowconcentration glue can be used to improve glue propagation along the feeding artery [7-12]. However, a wedged microcatheter position cannot be always obtained and may sometimes cause dissection which can even preclude the possibility of further embolization. In this study we present a novel, two-catheter technique for liquid agent embolization that resulted in 
safe and effective occlusion of AVF shunts.

\section{MATERIALS and METHODS}

Between January and May of 2013, we treated four patients with AVF using the two catheter technique of glue embolization under coil protection. Clinical data regarding the patients are summarized in Table 1. The patient cohort consisted of three males and one female from 37 to 82 years of age. The AVF diagnosis was spinal dural AVF (SDAVF) $(\mathrm{n}=2)$ with progressive neurological deficit associated with congestive venous myelopathy (Fig. 1), cervical paraspinal AVF $(n=1)$ with almost a single whole AVF, and facial arteriovenous malformation $(\mathrm{n}=1)$ with a large AVF component with branching pattern (Fig. 2).

All patients underwent MRI and digital subtraction angiography (DSA) examination before their treatment. On MRI, both of the patients with SDAVFs showed intramedullary hyperintense edema on T2WI and with swelling of the spinal cord combined with flow voids of dilated perimedullary veins $[13,14]$. As for patients with SDAVFs, a complete spinal angiographic examination and selective angiograms of AVF feeding arteries with $3 \mathrm{D}$ reconstruction were performed to identify the exact location of the AVFs and the angioarchitecture of the lesions [15]. Selective angiograms for the patient with facial lesion included bilateral internal carotid arteries, external carotid arteries, and vertebral arteries. The decision to use this technique was based on the tortuous angio-architecture and the high-flow hemodynamic of the lesions. All lesions were supplied by a dominant feeding artery with small and tortuous angio-architecture (spinal lesion) (Fig. 1) or they had a large feeder with a multiple branching pattern for which selective catheter engagement in a single branch could not lead to effective obliteration of the shunt (facial lesion) (Fig. 2).

\section{Interventional techniques}

All procedures were performed using the femoral approach, with the patients under general anesthesia to minimize patient motion and optimize DSA and roadmapping, and being systemically anticoagulated to an activated clotting time of $200-250$ s. Selective angiography of the feeding artery was performed to check the angio-architecture and the hemodynamics of the lesions.

Technical concept diagram of two microcatheter technique was illustrated in Fig. 3. Under digital roadmapping guidance, a glue delivering microcatheter was navigated into the parent artery and the tip was positioned as closely as possible to the AVF. A selective angiogram was obtained using the microcatheter. A coil delivery microcatheter was placed in the proximal portion of the feeding artery just below the first microcatheter tip (Fig. 3A). One to four coils were used to arrest the flow according to the diameter of the feeding artery. A selective angiogram through the first glue delivery microcatheter was obtained, and the flow stagnancy after coiling was compared to that seen in the previous selective angiogram obtained before coiling.

Once there was sufficient flow stagnancy, coil embolization was stopped with the last coil undetached (Fig. 3B). The appropriate mixture of glue (a mixture

Table1. Summary of patients with AVF

\begin{tabular}{|c|c|c|c|c|c|c|c|c|}
\hline No. & $\begin{array}{l}\text { Age/ } \\
\text { Sex }\end{array}$ & $\begin{array}{l}\text { Diagnosis and } \\
\text { lesion location }\end{array}$ & Presenting symptoms & $\begin{array}{l}\text { Feeding } \\
\text { artery }\end{array}$ & $\begin{array}{l}\text { Dia. } \times \text { length of } \\
\text { used coil }(\mathrm{mm})\end{array}$ & $\begin{array}{l}\text { Glue } \\
\text { Concentration }\end{array}$ & $\begin{array}{l}\text { Outcome } \\
\text { of AVFs }\end{array}$ & $\mathrm{FU}(\mathrm{m})$ \\
\hline 1 & $53 / \mathrm{M}$ & $\begin{array}{l}\text { Spinal DAVF } \\
\text { at C1 level }\end{array}$ & $\begin{array}{l}\text { Pain and sensory changes } \\
\text { in the neck, both shoulders, } \\
\text { and in the upper extremities. }\end{array}$ & $\begin{array}{l}\text { Left C1 } \\
\text { segmental artery }\end{array}$ & $1.5 \times 6$ & $33 \%$ & Cure & 4 \\
\hline 2 & $82 / \mathrm{M}$ & $\begin{array}{l}\text { Spinal DAVF } \\
\text { at T8 }\end{array}$ & $\begin{array}{l}\text { Pain and weakness in } \\
\text { both legs }\end{array}$ & $\begin{array}{l}\text { Left T8 } \\
\text { segmental artery }\end{array}$ & $\begin{array}{l}1 \times 3,1.5 \times 4 \\
2 \times 2,2 \times 4\end{array}$ & $25 \%$ & Cure & 3 \\
\hline 3 & $42 / \mathrm{M}$ & Facial AVM & $\begin{array}{l}\text { Oral ulcer with bleeding } \\
\text { due to a swollen pulsatile } \\
\text { facial mass }\end{array}$ & Facial artery & $4 \times 12,4 \times 4.1$ & $25 \%$ & Cure & 3 \\
\hline 4 & $37 / F$ & $\begin{array}{l}\text { Paraspinal } \\
\text { AVF at C3 }\end{array}$ & $\begin{array}{l}\text { Subcutaneous pulsatile } \\
\text { mass in the posterior neck } \\
\text { after a car accident }\end{array}$ & $\begin{array}{l}\text { Left deep } \\
\text { cervical artery }\end{array}$ & $1.5 \times 6,1.5 \times 6$ & $33 \%$ & Cure & 1 \\
\hline
\end{tabular}

Abbreviations: Dia, diameter; AVF, arteriovenous fistula; FU, follow-up; DAVF, dural arteriovenous AVF; AVM, arteriovenous malformation 
of 25 33\% glue Glubran 2/Lipiodol) was prepared depending on the AVF size and flow speed. The endpoint of the glue embolization was the occlusion of the AVF as well as that of the adjacent draining vein. At the end of glue injection, retrieval of the glue delivery microcatheter was followed by retrieval of the coil delivery microcatheter after the last coil was detached (Fig. $3 \mathrm{C} \& \mathrm{D}$ ). The control angiogram was obtained to identify the AVF occlusion as well as the presence of any residual AVF.

\section{RESULTS}

The results and the follow-up findings are shown in Table 1. Complete AVF occlusion was seen in all patients on the control angiograms obtained immediately following the embolization. There was no sign of over-penetration of the glue beyond the proximal draining vein during or after the embolization, and no procedure-related neurologic complications or recurrent DAVFs were observed. All patients' clinical symptoms improved following the procedure. Followup MRI showed a decrease or the disappearance of entangled perimedullary veins as well as that of congestive myelopathy in both SDAVF patients. Bruit disappeared in the patient with a paraspinal AVF. Bleeding with ulceration stopped and facial swelling subsided in the patient with facial arteriovenous malformation (AVM).

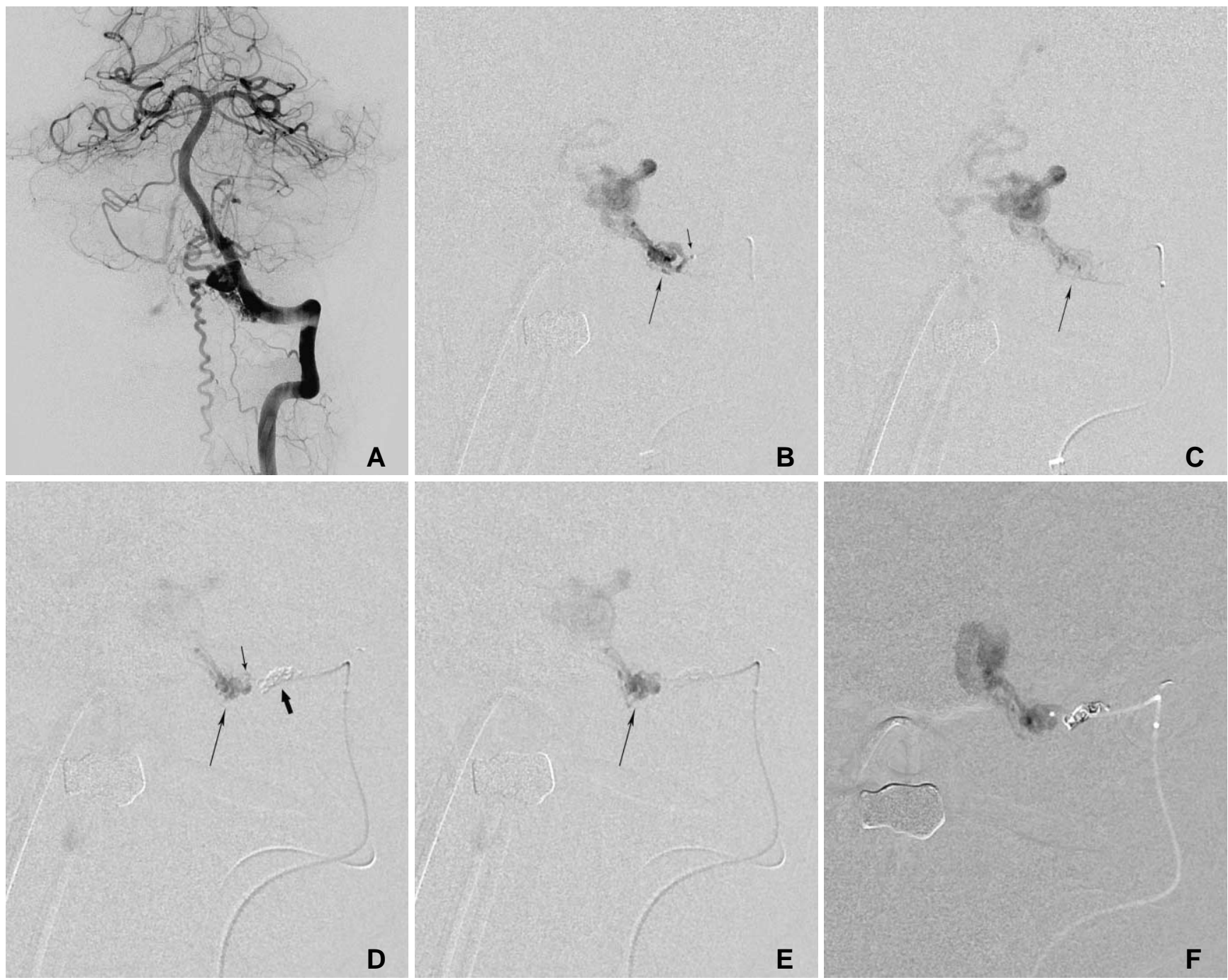

Fig, 1. A 53-year-old man presented with pain and sensory changes in the neck, both shoulders, and the upper extremities. A. Left vertebral angiogram shows a dural arteriovenous AVF at the C1 level. Note the perimedullary venous drainage. B \& $\mathbf{C}$. Selective angiogram obtained within a microcatheter (short, thin arrow in B) shows a AVF which reveals rapid washout of contrast agent due to the arterial inflow (long thin arrows in B \& C). D \& E. Same selective angiogram obtained after coiling (thick arrow in E) of the proximal feeder shows stagnant flow in the AVF (long, thin arrows in D \& E). F. Note that the glue cast exactly fills the AVF and the adjacent vein. 

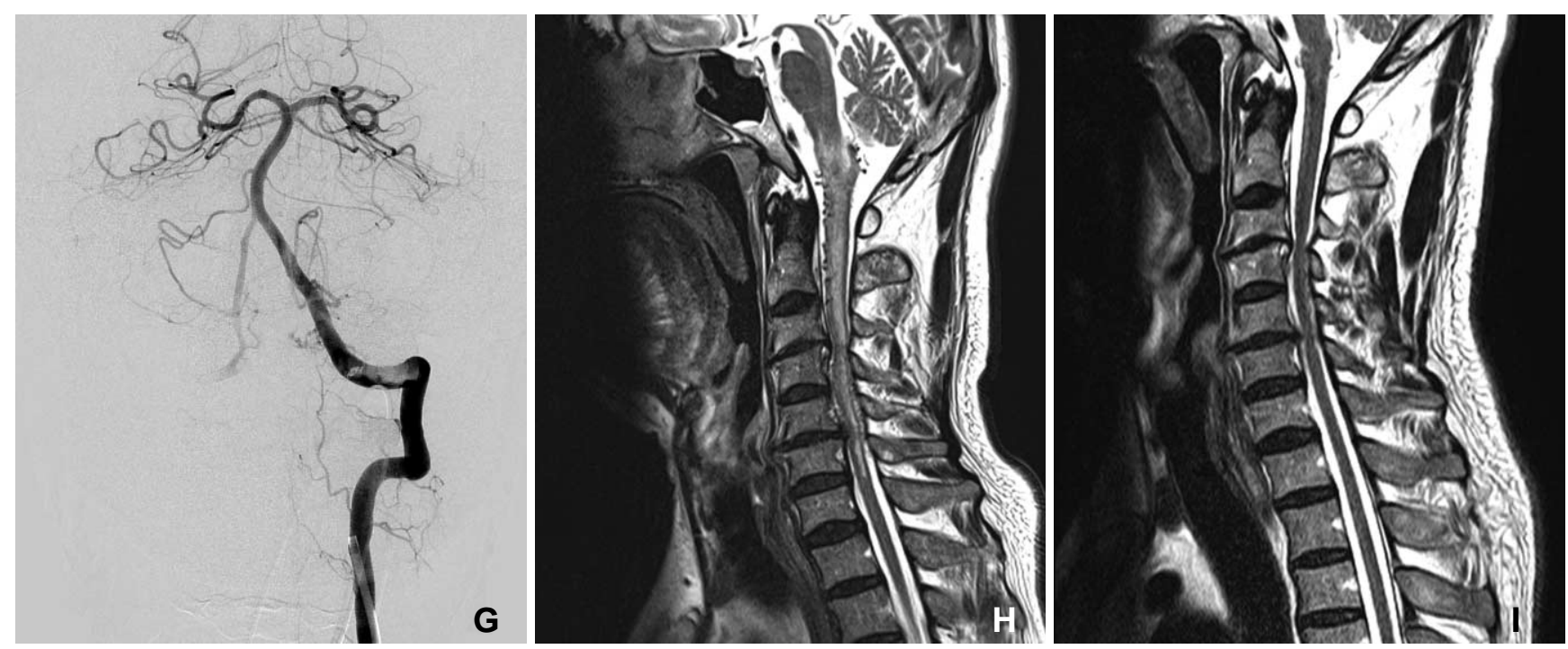

Fig. 1. G. Left vertebral angiogram obtained after glue embolization showed no residual AVF. H \& I. Comparison of the initial and the follow-up MRIs obtained three months later, shows complete disappearance of the intramedullary hyperintense edema caused by congestive venous myelopathy of the cervical spinal cord, as shown on T2WI with improvement of his symptoms.

\section{Case illustration}

A 53-year-old man presented with pain in the neck, both shoulders, and in the upper extremities. A vertebral angiogram showed SDAVF at the level of C1, supplied by the left $\mathrm{C} 1$ segmental artery and draining into the perimedullary and perimesencephalic veins (Fig. 1). Under general anesthesia a 6F guide catheter was placed into the left vertebral artery. At first, we considered two flow-control strategies: (1) temporary vertebral artery occlusion by a balloon placed at the origin of the $\mathrm{C} 1$ feeder; and (2) temporary balloon occlusion by a small balloon catheter placed in the $\mathrm{C} 1$ feeder. However, it was not possible to use either of these techniques because the VA at the curved angle was not fitted by a 4- or 5-mm compliant balloon and a small balloon catheter could not be introduced into the C1 feeder. Finally we decided to use the two catheter technique.

Two microcatheters were introduced into the site of the AVF and were positioned with approximately a 5$\mathrm{mm}$ tip distance between them. A repeat angiogram of the glue embolization microcatheter indicated a significant decrease of the AVF flow after a $1.5-\mathrm{mm} \times 6-\mathrm{cm}$ coil was introduced without detachment into the feeding artery. After obtaining a selected angiogram of $\mathrm{C} 1$ artery to make sure that the glue embolization was safe, a 33\% glue lipiodol mixture was infused into the AVF. The reflux of the glue filled only a portion of the area between the AVF and the coil which allowed the glue to have good penetration into the vein through the AVF. When the glue embolization was finished, the control angiogram using the guiding catheter showed complete occlusion of the AVF. The coil was then detached and the coil embolization microcatheter was retrieved (Fig. 1).

\section{DISCUSSION}

N-butyl cyanoacrylate has been used for transarterial embolization of AVFs due to the advantages of its easy preparation, effective delivery, good penetration, and permanent occlusion of AVF. However, there have been two risks related to glue embolization of a shunt lesion. Early blockage or premature polymerization of the glue at the proximal feeder without reaching the AVF site results in incomplete embolization of the AVF and develops other feeders by using adjacent branches of collaterals. Over-penetration or migration of glue cast into the venous side of the AVF is another potential risk of glue embolization, especially in a high-flow AVF [4].

The two catheter technique used in this study provides slow and steady glue cast formation by controlling the AVF flow speed, while coiling of the feeder induces stagnant shunt flow. This induced flow reduction effect using the two catheter technique could maximize the advantage of the glue embolization effect which can be used not only for high-flow AVF but also for AVF requiring low-concentration glue embolization for good penetration. In addition to reducing the shunt flow, coiling of the proximal feeder has several additional effects. Firstly, when there was only a short 

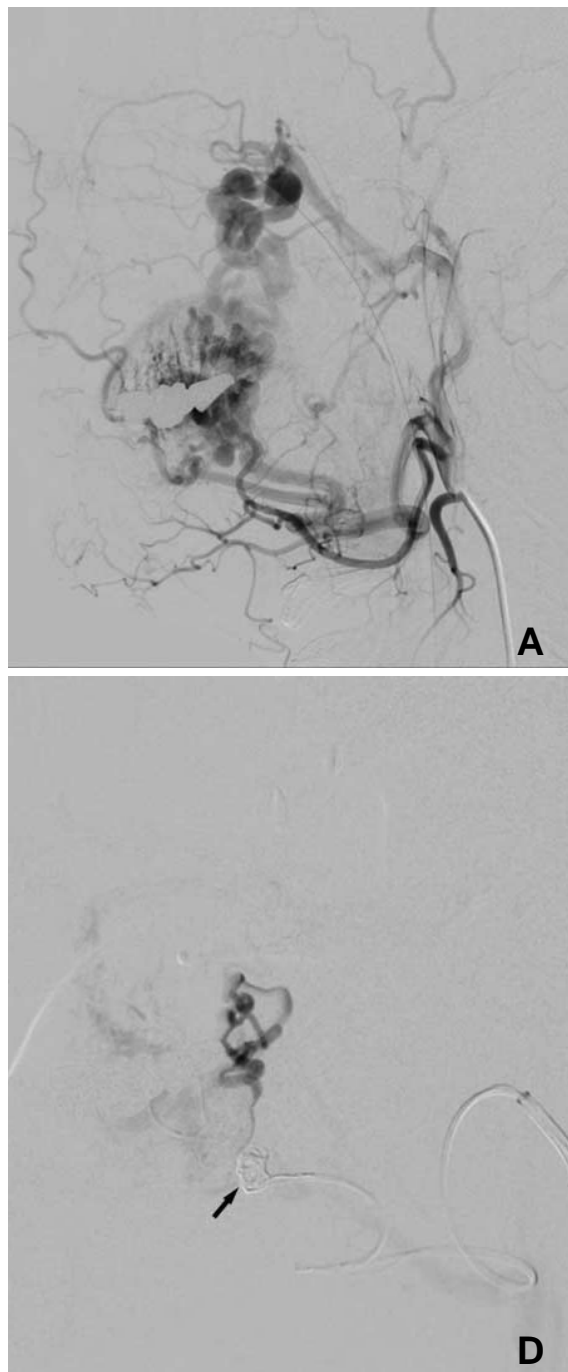

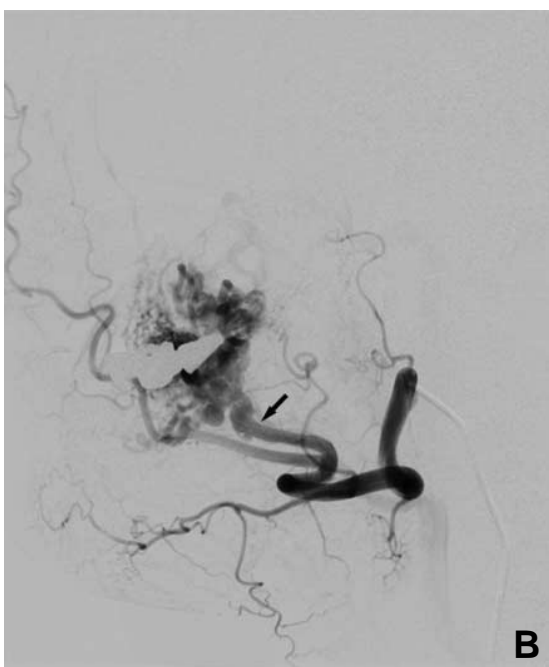

B
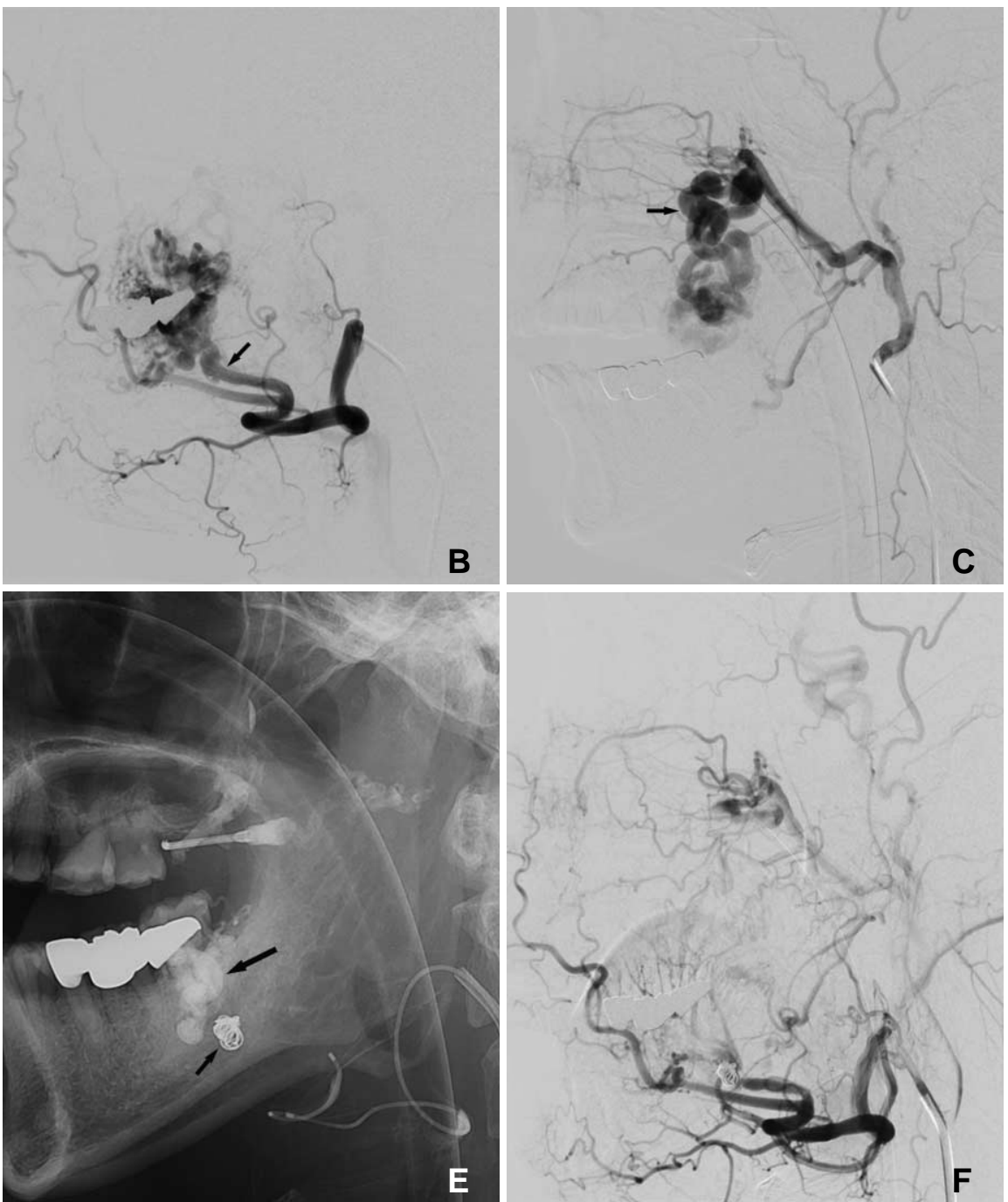

Fig. 2. A 42-year-old male presented with repeated ulcerative oral mucosal bleeding for 5 years. A. Left external carotid arteriogram shows an arteriovenous malformation in left cheek area. B. Left facial arteriogram shows an entangled vascular mass supplied by jugal branch (arrow) of the facial artery which is also supplied by branches (arrow) of the internal maxillary artery in figure C. Note dilated and tortuous feeders which preclude a microcatheter to reach the nidus. D. Distal microcatheter angiogram was obtained after proximal coiling (arrow) by proximal microcatheter after intra-arterial gelfoam and direct puncture glue embolizations in the lesion supplied by the internal maxillary artery. E. Note penetrated glue (a large arrow) beyond the protective coils (a small arrow). F. Final angiogram revealed no residual shunt and feeders. His oral ulcerative bleeding and mass effect in the cheek has improved so that further surgical resection was not required. There was no recurrence of ulceration or bleeding on 12 months follow-up period.

feeder stump from the vertebral artery at the $\mathrm{C} 1$ level, as seen in patient 1 with SDAVF, coiling of the feeder can protect inadvertent glue regurgitation into the parent vertebral artery. Second, when the glue microcatheter is retrieved through the coil mass, glue cast which might have become attached to the glue microcatheter tip could be trapped by the coil as a function of cleaning the tip of the glue-delivering microcatheter and excluding the possibility of inadvertent migration of the glue cast [16]. Third, retrieval of the glue catheter can be aided by an undetached coil and a coil microcatheter which maintain the position of the vessel configuration and with less stretching of the glued microcatheter which is sometimes difficult to retrieve because of gluing of the tip to the glue microcatheter and the vessel wall.

The two catheter technique seemed to be useful in treating several shunt lesions. One good indication is for AVF with a single, small, tortuous feeder, regardless of the flow amount, as used in the embolization of SDAVF in which selective catheterization to the AVF site is sometimes impossible and thus subsequent surgical resection needs to follow. Another indication would be for a large feeder with a multiple branching pattern of shunt feeders, as seen in our patient with facial AVM, because blocking the arterial inflow by 

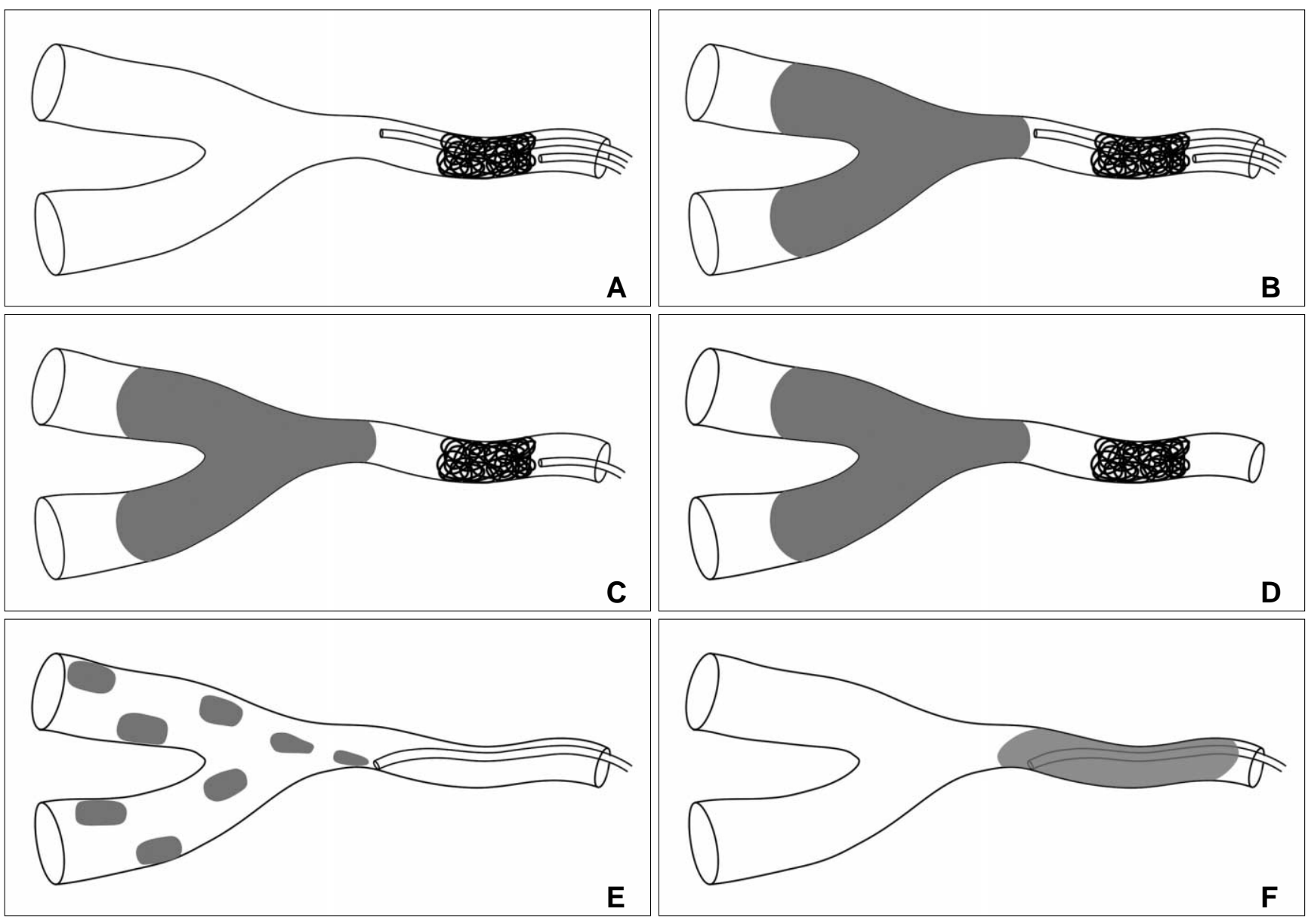

Fig. 3. Concept diagram of the two catheter technique. A. Two microcatheters are introduced into the site of the AVF feeder. AVF flow is controlled by coiling via the proximal catheter. B. Stable embolization is done by liquid embolic agent via the distal microcatheter. C. At the end of embolization, the distal microcatheter is removed under the support of the proximal catheter with undetached coil. D. The proximal microcatheter is removed after detachment of coil. E \& F. Direct injection of liquid embolic agent with low concentration leads to migration of embolic agent into the vein without effective occlusion of AVF or regurgitation of embolic cast to the proximal feeder without effective penetration of the AVF.

coiling could both prevent premature polymerization and promote the advancement of low-concentration glue cast into multiple shunt lesions without reflux into the proximal feeder. [17] In this flow-controlled, lowconcentration glue injection environment, proceeding of the glue cast into the shunt or vein depends on the injection force of the glue syringe, just like changing the Onyx spreading direction through stopping and reinjecting it, because much longer controlled injection time is possible.

The wedged microcatheter technique was reported to also possibly be able to establish flow arrest conditions which allow controlled permeation of the glue into the venous drainage route $[2,3,18]$. This technique was used to treat low-flow DAVFs using low-concentration glue by wedging a microcatheter tip in a small feeding vessel. However, it cannot be used when there is no small feeding vessel or the flow rate of the AVF is high.
In terms of adverse events, our clinical experience shows that this technique is a safe method of flow control for glue embolization of SDAVFs. Some of the most commonly anticipated complications of transarterial embolization like ischemic cranial nerve palsy and transcollateral migration of the liquid embolic agents were not occurred in our patients. Careful consideration of each patient's anatomy and use of the flow control technique with coil protection prevented such complications in our series.

There are some difficulties and precautions to be taken in order to avoid potential risks when using this technique. It is sometimes difficult to introduce two microcatheters into a small feeder, especially in SDAVF. In addition, glue propagation along intersegmental anastomosis should be avoided as it may cause inadvertent glue embolization of the adjacent normal spinal artery [19]. It is also worthy of note that 


\section{Lin-Bo Zhao, et al.}

complete flow arrest cannot be achieved by coiling of the feeder through which a microcatheter is passing. Therefore, selective angiograms before and after coiling should be compared in order to determine how much stagnant flow effect was achieved.

We found that the two microcatheter technique used by positioning one glue microcatheter beyond another coil microcatheter, was safe and effective for glue embolization of AVF. This technique is especially effective for embolizing a small tortuous feeder, such as that found in SDAVF.

\section{References}

1. Kim DJ, Willinsky RA, Krings T, Agid R, Terbrugge K. Intracranial dural arteriovenous shunts: transarterial glue embolization--experience in 115 consecutive patients. Radiology 2011;258:554-561

2. Li MH, Tan HQ, Fang C, Zhu YQ, Wang W, Wang J, et al. Transarterial embolisation therapy of dural carotid-cavernous AVFe using low concentration n-butyl-cyanoacrylate. Acta Neurochir (Wien) 2008;150:1149-1156

3. Liu HM, Huang YC, Wang YH, Tu YK. Transarterial embolisation of complex cavernous sinus dural arteriovenous AVFe with low-concentration cyanoacrylate. Neuroradiology 2000;42:766770

4. Suh DC, Kim JH, Lee MS, Park S, Kim ST, Choi CG, et al. Penetration Difference of n-Butyl2-Cyanoacrylate into the Nidus in the Embolisation of Brain Arteriovenous Malformation. Interv Neuroradiol 1998;4:63-74

5. Choi BS, Park JW, Kim JL, Kim SY, Park YS, Kwon HJ, et al. Treatment Strategy Based on Multimodal Management Outcome of Cavernous Sinus Dural Arteriovenous AVF (CSDAVF). Neurointervention 2011;6:6-12

6. Rodesch G, Hurth M, Alvarez H, Tadie M, Lasjaunias P. Spinal cord intradural arteriovenous AVFe: anatomic, clinical, and therapeutic considerations in a series of 32 consecutive patients seen between 1981 and 2000 with emphasis on endovascular therapy. Neurosurgery 2005;57:973-983

7. Jagadeesan BD, Grigoryan M, Hassan AE, Grande AW, Tummala RP. Endovascular Balloon-Assisted Embolization of Intracranial and Cervical Arteriovenous Malformations Using Dual Lumen Co-axial Balloon Microcatheters and Onyx: Initial Experience. Neurosurgery 2013 Feb 25. [Epub ahead of print]
8. Cohen JE, Moscovici S, Itshayek E. The advantages of balloon assistance in endovascular embolization of spinal dural arteriovenous AVFs. J Clin Neurosci 2013;20:141-143

9. Shi ZS, Loh Y, Gonzalez N, Tateshima S, Feng L, Jahan R, et al. Flow control techniques for Onyx embolization of intracranial dural arteriovenous AVFe. J Neurointerv Surg 2012;5:311-316

10. Andreou A, Ioannidis I, Nasis N. Transarterial balloon-assisted glue embolization of high-flow arteriovenous AVFs. Neuroradiology 2008;50:267-272

11. Luo CB, Teng MM, Chang FC, Chang CY. Endovascular treatment of intracranial high-flow arteriovenous AVFs by Guglielmi detachable coils. J Chin Med Assoc 2006;69:80-85

12. Nesbit GM, Barnwell SL. The use of electrolytically detachable coils in treating high-flow arteriovenous AVFs. AJNR Am J Neuroradiol 1998;19:1565-1569

13. Lee C-S, Pyun HW, Chae EY, Kim K-K, Rhim SC, Suh DC. Reversible Aggravation of Neurological Deficits after Steroid Medication in Patients with Venous Congestive Myelopathy Caused by Spinal Arteriovenous Malformation. Interventional Neuroradiology 2009;15:325-329

14. Krings T, Lasjaunias PL, Hans FJ, Mull M, Nijenhuis RJ, Alvarez $\mathrm{H}$, et al. Imaging in spinal vascular disease. Neuroimaging Clin $N$ Am 2007; 17:57-72

15. Suh DC, Kim HS, Baek HJ, Park JW, Kim KK, Rhim SC. Angioarchitecture of Spinal Dural Arteriovenous AVF Evaluation with 3D Rotational Angiography. Neurointervention 2012;7:10-16

16. Suh DC, Kim KS, Lim SM, Shi HB, Choi CG, Lee HK, et al. Technical feasibility of embolizing aneurysms with glue (N-butyl 2-cyanoacrylate): experimental study in rabbits. AJNR Am J Neuroradiol 2003;24:1532-1539

17. Suh DC, Choi CG, Sung KB, Kim KK, Rhim SC. Spinal osseous epidural arteriovenous AVF with multiple small arterial feeders converging to a round AVFr nidus as a target of venous approach. AJNR Am J Neuroradiol 2004;25:69-73

18. Nelson PK, Russell SM, Woo HH, Alastra AJ, Vidovich DV. Use of a wedged microcatheter for curative transarterial embolization of complex intracranial dural arteriovenous AVFs: indications, endovascular technique, and outcome in 21 patients. J Neurosurg 2003;98:498-506

19. Shi HB, Suh DC, Lee HK, Lim SM, Kim DH, Choi CG, et al. Preoperative transarterial embolization of spinal tumor: embolization techniques and results. AJNR Am J Neuroradiol 1999;20: 2009-2015 